University of New Mexico

UNM Digital Repository

Mathematics and Statistics Faculty and Staff

Publications

Academic Department Resources

$4-2018$

\title{
Strong Degrees in Single Valued Neutrosophic Graphs
}

\author{
Florentin Smarandache \\ University of New Mexico, smarand@unm.edu
}

Said Broumi

Assia Bakali

Seema Mehra

Mohamed Talea

See next page for additional authors

Follow this and additional works at: https://digitalrepository.unm.edu/math_fsp

Part of the Analysis Commons, Discrete Mathematics and Combinatorics Commons, Logic and Foundations Commons, Other Mathematics Commons, and the Set Theory Commons

\section{Recommended Citation}

Smarandache, Florentin; Said Broumi; Assia Bakali; Seema Mehra; Mohamed Talea; and Manjeet Singh. "Strong Degrees in Single Valued Neutrosophic Graphs." Future of Information and Communication Conference (FICC) 2018 5-6 April 2018 / Singapore (2018): 1-9. https://digitalrepository.unm.edu/ math_fsp/415

This Article is brought to you for free and open access by the Academic Department Resources at UNM Digital Repository. It has been accepted for inclusion in Mathematics and Statistics Faculty and Staff Publications by an authorized administrator of UNM Digital Repository. For more information, please contact amywinter@unm.edu, Isloane@salud.unm.edu, sarahrk@unm.edu. 


\section{Authors}

Florentin Smarandache, Said Broumi, Assia Bakali, Seema Mehra, Mohamed Talea, and Manjeet Singh 


\section{Strong Degrees in Single Valued Neutrosophic Graphs}

\author{
Said Broumi \\ Laboratory of Information \\ Processing, Faculty of Science Ben \\ M'Sik, University Hassan II, B.P \\ 7955, Sidi Othman, Casablanca, \\ Morocco \\ broumisaid78@gmail.com \\ Mohamed Talea \\ Laboratory of Information \\ Processing, Faculty of Science Ben \\ M'Sik, University Hassan II, B.P \\ (7955, Sidi Othman, Casablanca, \\ Morocco) taleamohamed@yahoo.fr
}

\author{
Assia Bakali \\ Ecole Royale Navale, Boulevard \\ Sour Jdid, B.P 16303 Casablanca, \\ Morocco \\ assiabakali@yahoo.fr
}

Florentin Smarandache

Department of Mathematics,

University of New Mexico, 705

Gurley Avenue, Gallup, NM, 87301,

USA

fsmarandache@gmail.com; smarand@unm.edu

\author{
Seema Mehra \\ Department of Mathematics, \\ Maharshi Dayanand \\ University, Rohtak, India \\ Sberwal2007@gmail.com; \\ mehra.seema@yahoo.co.in
}

\author{
Manjeet Singh \\ Department of Mathematics, \\ K.L.P.College, Rewari, Rohtak, \\ India \\ manjeetmaths@gmail.com
}

\begin{abstract}
The concept of single valued neutrosophic graphs (SVNGs) generalizes the concept of fuzzy graphs and intuitionistic fuzzy graphs. The purpose of this research paper is to define different types of strong degrees in SVNGs and introduce novel concepts, such as the vertex truth-membership, vertex indeterminacy-membership and falsity-membership sequence in SVNG with proof and numerical illustrations.
\end{abstract}

Keywords-Single valued neutrosophic graph (SVNG); neutrosophic set; sequence; strong degree

\section{INTRODUCTION}

In [1], [3] Smarandache explored the notion of neutrosophic sets (NS in short) as a powerful tool which extends the concepts of crisp set, fuzzy sets and intuitionistic fuzzy sets [2]-[6]. This concept deals with uncertain, incomplete and indeterminate information that exist in real world. The concept of NS sets associate to each element of the set a degree of membership $T_{A}(x)$, a degree of indeterminacy $I_{A}(x)$ and a degree of falsity $F_{A}(x)$, in which each membership degree is a real standard or non-standard subset of the nonstandard unit ] $0,1^{+}$[. Smaranadache [1], [2] and Wang [7] defined the concept of single valued neutrosophic sets (SVNS), an instance of NS, to deal with real application. In [8], the readers can found a rich literature on SVNS.

In more recent times, combining the concepts of NSs, interval valued neutrosophic sets (IVNSs) and bipolar neutrosophic sets with graph theory, Broumi et al. introduced various types of neutrosophic graphs including single valued neutrosophic graphs (SVNGs for short) [9], [11], [14], interval valued neutrosophic graphs [13], [18], [20], bipolar neutrosophic graphs [10], [12], all these graphs are studied deeply. Later on, the same authors presented some papers for solving the shortest path problem on a network having single valued neutrosophic edges length [17], interval valued neutrosophic edge length [32], bipolar neutrosophic edge length [21], trapezoidal neutrosophic numbers [15], SVtrapezoidal neutrosophic numbers [16], triangular fuzzy neutrosophic [19].Our approach of neutrosophic graphs are different from that of Akram et al. [26]-[28] since while Akram considers, for the neutrosophic environment $(<=,<=$, $>=)$ we do $(<=,>=,>=)$ which is better, since while $\mathrm{T}$ is a positive quality, I, F are considered negative qualities. Akram et al. include "I" as a positive quality together with "T". So our papers improve Akram et al.'s papers. After that, several authors are focused on the study of SVNGs and many extensions of SVNGs have been developed. Hamidi and Borumand Saeid [25] defined the notion of accessible-SVNGs and apply it social networks. In [24], Mehra and Manjeet defined the notion of single valued neutrosophic signed graphs. Hassan et al. [30] proposed some kinds of bipolar neutrosophic graphs. Naz et al. [23] studied some basic operations on SVNGs and introduced vertex degree of these operations for SVNGs and provided an application of single valued neutrosophic digraph (SVNDG) in travel time. Ashraf et al. [22] defined new classes of SVNGs and studied some of its important properties. They solved a multi-attribute decision making problem using a SVNDG. Mullai [31] solved the spanning tree problem in bipolar neutrosophic environment and gave a numerical example.

Motivated by the Karunambigai work's [29].The concept of strong degree of intuitionistic fuzzy graphs is extended to strong degree of SVNGs

This paper has been organized in five sections. In Section 2, we firstly review some basic concepts related to neutrosophic set, single valued neutrosophic sets and SVNGs. In Section 3, different strong degree of SVNGs are proposed and studied with proof and example. In Section 4, the concepts of vertex truth-membership, vertex indeterminacy- 
membership and vertex falsity- membership is discussed. Lastly, Section 5 concludes the paper.

\section{PRELIMINAREIS AND DEFINTIONS}

In the following, we briefly describe some basic concepts related to neutrosophic sets, single valued neutrosophic sets and SVNGs.

Definition 2.1 [1] Given the universal set $\zeta$. A neutrosophic set $A$ on $\zeta$ is characterized by a truth membership function $T_{A}$, an indeterminacy membership function $I_{A}$ and falsity membership function $F_{A}$, where $\left.T_{A}, I_{A}, F_{A}: \zeta \rightarrow\right]^{-} 0,1^{+}\left[\right.$. For all $\mathrm{x} \in \zeta, \mathrm{x}=\left(\mathrm{x}, T_{A}(x), I_{A}(x), F_{A}(x)\right) \in$ $\mathrm{A}$ is neutrosophic element of $\mathrm{A}$.

The neutrosophic set can be written in the following form:

$\mathrm{A}=\left\{<\mathrm{x}: T_{A}(x), I_{A}(x), F_{A}(x)>, \mathrm{x} \in \zeta\right\}$

with the condition

$-0 \leq T_{A}(x)+I_{A}(x)+F_{A}(x) \leq 3^{+}$

Definition 2.2 [7] Given the universal set $\zeta$. A single valued neutrosophic set $A$ on $\zeta$ is characterized by a truth membership function $T_{A}$, an indeterminacy membership function $I_{A}$ and falsity membership function $F_{A}$, where $T_{A}, I_{A}, F_{a}: \zeta \rightarrow[0,1]$. For all $\mathrm{x} \in \zeta, \mathrm{x}=(\mathrm{x}$, $\left.T_{A}(x), I_{A}(x), F_{A}(x)\right) \in \mathrm{A}$ is a single valued neutrosophic element of $\mathrm{A}$.

The single valued neutrosophic set can be written in the following form:

$$
\mathrm{A}=\left\{<\mathrm{x}: T_{A}(x), I_{A}(x), F_{A}(x)>, \mathrm{x} \in \zeta\right\}
$$

with the condition

$$
0 \leq T_{A}(x)+I_{A}(x)+F_{A}(x) \leq 3
$$

Definition 2.3 [14] ASVN-graph $G$ is of the form $\mathrm{G}=(\mathrm{A}, \mathrm{B})$ where $\mathrm{A}$

1. $\mathrm{A}=\left\{v_{1}, v_{2}, \ldots v_{n}\right\}$ Such that the functions $T_{A}: \mathrm{A} \rightarrow[0,1]$, $I_{A}: A \rightarrow[0,1], F_{A}: \mathrm{A} \rightarrow[0,1]$ denote the truth-membership function, an indeterminacy-membership function and falsitymembership function of the element $v_{i} \in$ A respectively and

$$
0 \leq t_{A}\left(v_{i}\right)+i_{A}\left(v_{i}\right)+f_{A}\left(v_{i}\right) \leq 3 \forall v_{i} \in A
$$

$\mathrm{i}=1,2, \ldots, \mathrm{n}$

$2 . \mathrm{B}=\left\{\left(v_{i}, v_{j}\right) ;\left(v_{i}, v_{j}\right) \in A \times A\right\}$ and the function $T_{B}: \mathrm{B} \rightarrow$ $[0,1]$,

$$
\begin{aligned}
& I_{B}: \mathrm{B} \rightarrow[0,1], F_{B}: \mathrm{B} \rightarrow[0,1] \text { are defined by } \\
& T_{B}\left(v_{i}, v_{j}\right) \leq \min \left(T_{A}\left(v_{i}\right), T_{A}\left(v_{j}\right)\right) \\
& I_{B}\left(v_{i}, v_{j}\right) \geq \max \left(I_{A}\left(v_{i}\right), I_{A}\left(v_{j}\right)\right) \\
& F_{B}\left(v_{i}, v_{j}\right) \geq \max \left(F_{A}\left(v_{i}\right), F_{A}\left(v_{j}\right)\right)
\end{aligned}
$$

Where $T_{B}, I_{B}, F_{B}$ denotes the truth-membership function, indeterminacy membership function and falsity membership function of the edge $\left(v_{i}, v_{j}\right) \in \mathrm{B}$ respectively where

$$
0 \leq T_{B}\left(v_{i}, v_{j}\right)+I_{B}\left(v_{i}, v_{j}\right)+F_{B}\left(v_{i}, v_{j}\right) \leq 3
$$

$$
\forall\left(v_{i}, v_{j}\right) \in B, \mathrm{i}, \mathrm{j} \in\{1,2, \ldots, \mathrm{n}\}
$$

$A$ is called the vertex set of $G$ and $B$ is the edge set of $G$.

The following Fig. 1 represented a graphical representation of single valued neutrosophic graph.

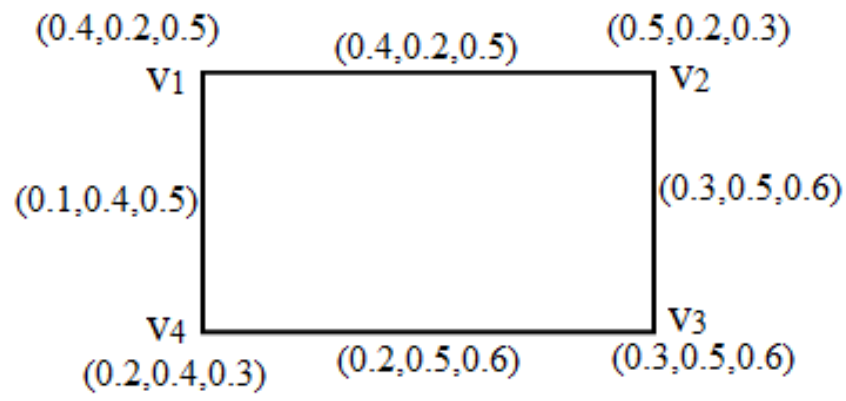

Fig. 1. Single valued neutrosophic graph.

\section{Strong Degree in Single Valuedneutrosophic GRAPH}

The following section introduces new concepts and proves their properties.

Definition 3.1 Given the SVN-graph $G=(V, E)$. The Tstrong degree of a vertex $v_{i} \in V$ is defined as $d_{s(T)}\left(v_{i}\right)=\sum_{e_{i j} \in E} T_{i j}, e_{i j}$ are strong edges incident at $v_{i}$.

Definition 3.2 Given the SVN-graph $G=(V, E)$. The Istrong degree of a vertex $v_{i} \in V$ is defined as $d_{s(I)}\left(v_{i}\right)=\sum_{e_{i j} \in E} I_{i j}, e_{i j}$ are strong edges incident at $v_{i}$.

Definition 3.3 Given the SVN-graph $\mathrm{G}=(\mathrm{V}, \mathrm{E})$. The Fstrong degree of a vertex $v_{i} \in V$ is defined as $d_{s(F)}\left(v_{i}\right)=\sum_{e_{i j} \in E} F_{i j}, e_{i j}$ are strong edges incident at $v_{i}$.

Definition3.4 Let $\mathrm{G}=(\mathrm{V}, \mathrm{E})$ be $\mathrm{SVNG}$. The strong degree of a vertex $\quad v_{i} \in V$ is as follow $d_{s}\left(v_{i}\right)=\left[\sum_{e_{i j} \in E} T_{i j}, \sum_{e_{i j} \in E} I_{i j}, \sum_{e_{i j} \in E} F_{i j}\right]$, where $e_{i j}$ are strong edge incident at $v_{i}$.

Definition 3.5 Let $\mathrm{G}=(\mathrm{V}, \mathrm{E})$ be a $\mathrm{SVNG}$. The minimum strong degree of $\mathrm{G}$ is defined as

$$
\begin{aligned}
& \delta_{s}(\mathrm{G})=\left(\delta_{s(T)}(\mathrm{G}), \delta_{s(I)}(\mathrm{G}), \delta_{s(F)}(\mathrm{G}),\right. \text { where } \\
& \delta_{s(\mathrm{~T})}(\mathrm{G})=\wedge\left\{d_{s(\mathrm{~T})}\left(\mathrm{v}_{i}\right) / \mathrm{v}_{i} \in V\right\} \text { is the minimum } \mathrm{T} \text { - }
\end{aligned}
$$
strong degree of $\mathrm{G}$. 
$\delta_{s(I)}(G)=\wedge\left\{d_{s(\mathrm{I})}\left(\mathrm{v}_{i}\right) / \mathrm{v}_{i} \in V\right\}$ is the minimum Istrong degree of $\mathrm{G}$.

$\delta_{s(F)}(G)=\wedge\left\{d_{s(F)}\left(\mathrm{v}_{i}\right) / \mathrm{v}_{i} \in V\right\}$ is the minimum $\mathrm{F}$ Strong degree of $\mathrm{G}$.

Definition 3.6 Given the SVN-graph $\mathrm{G}=(\mathrm{V}, \mathrm{E})$. The maximum strong degree of $\mathrm{G}$ is defined as

$$
\Delta_{s}(G)=\left(\Delta_{s(\mathrm{~T})}(\mathrm{G}), \Delta_{s(\mathrm{I})}(\mathrm{G}), \Delta_{s(\mathrm{~F})}(\mathrm{G})\right) \text {, where }
$$

$\Delta_{s(T)}(G)=\vee\left\{d_{s(\mathrm{~T})}\left(\mathrm{v}_{i}\right) / \mathrm{v}_{i} \in V\right\}$ is the maximum $\mathrm{T}$ strong degree of $\mathrm{G}$.

$\Delta_{s(I)}(G)=\vee\left\{d_{s(I)}\left(\mathrm{v}_{i}\right) / \mathrm{v}_{i} \in V\right\}$ is the maximum Istrong degree of $\mathrm{G}$.

$\Delta_{s(\mathrm{~F})}(\mathrm{G})=\vee\left\{d_{s(\mathrm{~F})}\left(\mathrm{v}_{i}\right) / \mathrm{v}_{i} \in V\right\}$ is the maximum $\mathrm{F}$ Strong degree of $\mathrm{G}$.

Definition 3.7 Let $\mathrm{G}$ be a SVNG, the T-total strong degree of a vertex $v_{i} \in V$ in $\mathrm{G}$ is defined as $t d_{s(\mathrm{~T})}\left(v_{i}\right)=d_{s(\mathrm{~T})}\left(v_{i}\right)+T_{i}$,

Definition 3.8 Let $\mathrm{G}$ be a SVNG, the I-total strong degree of a vertex in $\mathrm{G}$ is defined as $v_{i} \in V$ $t d_{s(\mathrm{I})}\left(v_{i}\right)=d_{s(\mathrm{I})}\left(v_{i}\right)+I_{i}$,

Definition 3.9 Let $\mathrm{G}$ be a SVNG, the F-total strong degree of a vertex $v_{i} \in V$ in $\mathrm{G}$ is defined $t d_{s(F)}\left(v_{i}\right)=d_{s(F)}\left(v_{i}\right)+F_{i}$,

Definition 3.10 Let $\mathrm{G}$ be a SVNG, the total strong degree of a vertex $v_{i} \in V$ in $\mathrm{G}$ is defined as

$$
t d_{s}\left(v_{i}\right)=\left[t d_{s(T)}\left(v_{i}\right), t d_{s(I)}\left(v_{i}\right), t d_{s(F)}\left(v_{i}\right)\right]
$$

Definition 3.11 Given the SVN-graph $\mathrm{G}=(\mathrm{V}, \mathrm{E})$. The minimum total strong degree of $\mathrm{G}$ is defined as

$$
\begin{aligned}
& \delta_{t s}(G)=\left(\delta_{t s(T)}(G), \delta_{t s(I)}(G), \delta_{t s(F)}(G)\right), \text { where } \\
& \delta_{t s(T)}(G)=\wedge\left\{d_{t s(T)}\left(\mathrm{v}_{i}\right) / \mathrm{v}_{i} \in V\right\} \text { is the minimum T- }
\end{aligned}
$$
total strong degree of $\mathrm{G}$.

$\delta_{t s(I)}(G)=\wedge\left\{d_{t s(\mathrm{I})}\left(\mathrm{v}_{i}\right) / \mathrm{v}_{i} \in V\right\}$ is the minimum $\mathrm{I}-$ total strong degree of $\mathrm{G}$.

$\delta_{t s(F)}(G)=\wedge\left\{d_{t s(F)}\left(\mathrm{v}_{i}\right) / \mathrm{v}_{i} \in V\right\}$ is the minimum Ftotal strong degree of $\mathrm{G}$.

Definition 3.12 Given the SVN-graph $G=(V, E)$. The maximum total strong degree of $\mathrm{G}$ is defined as:

$$
\Delta_{t s}(G)=\left(\Delta_{t s(T)}(G), \Delta_{t s(I)}(\mathrm{G}), \Delta_{t s(F)}(G)\right) \text {, where }
$$

$\Delta_{t s(T)}(\mathrm{G})=v\left\{d_{t s(\mathrm{~T})}\left(\mathrm{v}_{i}\right) / \mathrm{v}_{i} \in V\right\}$ is the maximum $\mathrm{T}$ total strong degree of $\mathrm{G}$.

$$
\Delta_{t s(I)}(G)=\vee\left\{d_{t s(I)}\left(\mathrm{v}_{i}\right) / \mathrm{v}_{i} \in V\right\} \text { is the maximum I- }
$$
total strong degree of $\mathrm{G}$.

$$
\Delta_{t s(\mathrm{~F})}(\mathrm{G})=\vee\left\{d_{t s(\mathrm{~F})}\left(\mathrm{v}_{i}\right) / \mathrm{v}_{i} \in V\right\} \text { is the maximum } \mathrm{F} \text { - }
$$
total strong degree of $\mathrm{G}$.

Definition 3.13 Given the SVN-graph $\mathrm{G}=(\mathrm{V}, \mathrm{E})$. The Tstrong size of a SVNG is defined as

$$
S_{s(T)}(G)=\sum_{v_{i} \neq v_{j}} T_{i j} \text { where }^{T_{i j}} \text { is the membership of strong }
$$
edge $e_{i j} \in E$.

Definition 3.14 Given the SVN-graph $\mathrm{G}=(\mathrm{V}, \mathrm{E})$. The Istrong size of a SVNG is defined as

$$
S_{s(I)}(G)=\sum_{v_{i} \neq v_{j}} I_{i j} \text { where } I_{i j} \text { is the indeterminacy- }
$$

membership of strong edge $e_{i j} \in E$.

Definition 3.15 Given the SVN-graph $\mathrm{G}=(\mathrm{V}, \mathrm{E})$. The Fstrong size of a SVNG is defined as

$$
S_{s(F)}(G)=\sum_{v_{i} \neq v_{j}} F_{i j} \text { where } F_{i j} \text { is the non-membership of }
$$

strong edge $e_{i j} \in E$

Definition 3.16 Given the SVN-graph $G=(V, E)$. The strong size of a SVNG is defined as

$$
S_{s}(G)=\left[S_{s(\mathrm{~T})}(\mathrm{G}), S_{s(\mathrm{I})}(\mathrm{G}), S_{s(F)}(\mathrm{G})\right]
$$

Definition 3.17 Given the SVN-graph $\mathrm{G}=(\mathrm{V}, \mathrm{E})$. The Tstrong order of a SVNG is defined as

$$
O_{s(T)}(G)=\sum_{v_{i} \in V} T_{i} \text { where } v_{i} \text { is the strong vertex in G. }
$$

Definition 3.18 Given the SVN-graph $\mathrm{G}=(\mathrm{V}, \mathrm{E})$. The Istrong order of a SVNG is defined as

$$
O_{s(\mathrm{I})}(G)=\sum_{v_{i} \in V} I_{i} \text { where } v_{i} \text { is the strong vertex in G. }
$$

Definition 3.19 Given the SVN-graph $\mathrm{G}=(\mathrm{V}, \mathrm{E})$. The Fstrong order of a SVNG is defined as

$$
O_{s(\mathrm{~F})}(G)=\sum_{v_{i} \in V} F_{i} \text { where } v_{i} \text { is the strong vertex in } \mathrm{G} \text {. }
$$

Definition 3.20 Given the SVN-graph $\mathrm{G}=(\mathrm{V}, \mathrm{E})$. The strong order of a SVNG is defined as

$$
O_{s}(G)=\left[O_{s(T)}(G), O_{s(I)}(G), O_{s(F)}(G)\right]
$$


Definition 3.21 Let $\mathrm{G}$ be a SVNG. If $d_{s(T)}\left(v_{i}\right)=k_{1}$, $d_{s(I)}\left(v_{i}\right)=k_{2}$ and,$d_{s(F)}\left(v_{i}\right)=k_{3}$ for all $\mathrm{v}_{i} \in V$, then the SVNG is called as $\left(k_{1}, k_{2}, k_{3}\right)$ - strong constant SVNG (or) Strong constant SVNG of degree $\left(k_{1}, k_{2}, k_{3}\right)$.

Definition 3.22 Let $\mathrm{G}$ be a SVNG. If $t d_{s(T)}\left(v_{i}\right)=r_{1}$, $t d_{s(I)}\left(v_{i}\right)=r_{2}$ and,$d_{s(\mathrm{~F})}\left(v_{i}\right)=r_{3}$ for all $\mathrm{v}_{i} \in V$, then the SVNG is called as $\left(r_{1}, r_{2}, r_{3}\right)$ - totally strong constant SVNG (or) totally strong constant SVNG of degree $\left(r_{1}, r_{2}, r_{3}\right)$.

Proposition 3.23 In a SVNG, G

$$
\begin{aligned}
& 2^{S_{s(T)}(G)}=\sum_{i=1}^{n} d_{s(T)}\left(v_{i}\right), 2^{S_{s(I)}(G)}=\sum_{i=1}^{n} d_{s(I)}\left(v_{i}\right) \text { and } \\
& 2^{S_{S(F)}(G)}=\sum_{i=1}^{n} d_{s(F)}\left(v_{i}\right)
\end{aligned}
$$

Proposition 3.24 In a connected SVNG,

1) $d_{S(T)}\left(\mathrm{v}_{\mathrm{i}}\right) \leq d_{T i}, d_{S(I)}\left(\mathrm{v}_{\mathrm{i}}\right) \leq d_{I i}$ and $d_{S(F)}\left(\mathrm{v}_{\mathrm{i}}\right) \leq d_{F i}$

2) $t d_{S(T)}\left(\mathrm{v}_{\mathrm{i}}\right) \leq t d_{T i}, t d_{S(I)}\left(\mathrm{v}_{\mathrm{i}}\right) \leq t d_{I i}$ and $\mathrm{t} d_{S(F)}\left(\mathrm{v}_{\mathrm{i}}\right) \leq t d_{\mathrm{Fi}}$.

Proposition 3.25 Let G be a SVNG where crisp graph $G^{*}$ is an odd cycle. Then $\mathrm{G}$ is strong constant if $\left.\mathrm{f}<T_{i j}, I_{i j}, F_{i j}\right\rangle$ is constant function for every $e_{i j} \in \mathrm{E}$.

Proposition 3.26 Let $\mathrm{G}$ be a SVNG where crisp graph $G^{*}$ is an even cycle. Then $G$ is strong constant if $\mathrm{f}<$ $T_{i j}, I_{i j}, F_{i j}>$ is constant function or alternate edges have same true membership, indeterminate membership and false membership for every $e_{i j} \in \mathrm{E}$.

Remark 3.27 The above proposition 3.25 and proposition 3.26 hold for totally strong constant $\mathrm{SVNG}$, if $<T_{i}, I_{i}, F_{i}>$ is a constant function.

Remark 3.28 A complete SVNG need not be a strong constant SVNG and totally strong constant SVNG.

Remark 3.29 A strong SVNG need not be a strong constant SVNG and totally strong constant SVNG.

Remark 3.30 For a strong vertex $v_{i} \in \mathrm{V}$,

1) $d_{T}\left(v_{i}\right)=d_{S T}\left(v_{i}\right), d_{I}\left(v_{i}\right)=d_{S I}\left(v_{i}\right)$ and $d_{F}\left(v_{i}\right)=d_{S F}\left(v_{i}\right)$

2) $t d_{T}\left(v_{i}\right)=t d_{S T}\left(v_{i}\right), t d_{I}\left(v_{i}\right)=t d_{S I}\left(v_{i}\right)$ and $\mathrm{t} d_{F}\left(v_{i}\right)=t d_{S F}\left(v_{i}\right)$

Theorem 3.31 Let $\mathrm{G}$ be a complete $\mathrm{SVNG}$ with $\mathrm{V}=$ $\left\{v_{1}, v_{2}, \ldots, v_{n}\right\}$ such that $T_{1} \leq T_{2} \leq T_{3} \leq \ldots \leq T_{n}, I_{1} \geq I_{2} \geq I_{3} \geq \ldots$ $\geq I_{n}$ and $F_{1} \geq F_{2} \geq F_{3} \geq \ldots \geq F_{n}$ Then

1) $T_{1 j}$ is minimum edge truth membership, $I_{1 j}$ is the maximum edge indeterminacy membership and $F_{1 j}$ is the maximum edge falsity membership of $e_{i j}$ emits from $v_{1}$ for all $\mathrm{j}=2,3,4, \ldots, \mathrm{n}$.

2) $T_{\text {in }}$ is maximum edge truth membership, $I_{\text {in }}$ is the minimum edge indeterminacy membership and $F_{\text {in }}$ is the minimum edge falsity membership of among all edges from emits from $v_{i}$ to $v_{n}$ for all $\mathrm{i}=1,2,3,4, \ldots, \mathrm{n}-1$.

3) $\mathrm{t} d_{T}\left(v_{1}\right)=\delta_{\mathrm{t} d}(\mathrm{G})=\mathrm{n} \cdot \mathrm{T}_{1}, \mathrm{t} d_{I}\left(v_{1}\right)=\Delta_{\mathrm{t} d_{I}}(\mathrm{G})=\mathrm{n} \cdot \mathrm{I}_{1}$ and $\mathrm{t} d_{F}\left(v_{1}\right)=\Delta_{\mathrm{t} d_{F}}(\mathrm{G})=\mathrm{n} . \mathrm{F}_{1}$.

4) $\mathrm{t} d_{T}\left(v_{n}\right)=\Delta_{\mathrm{t} d_{T}}(\mathrm{G})=\sum_{i=1}^{n} \mathrm{~T}_{\mathrm{i}}, \mathrm{t} d_{I}\left(v_{n}\right)=\delta_{\mathrm{t} d_{I}}(\mathrm{G})=$ $\sum_{i=1}^{n} \mathrm{I}_{\mathrm{i}}$, and $\mathrm{t} d_{F}\left(v_{n}\right)=\delta_{\mathrm{t} d_{F}}(\mathrm{G})=\sum_{i=1}^{n} \mathrm{~F}_{\mathrm{i}}$.

Proof: Throughout the proof, suppose that $T_{1} \leq T_{2} \leq T_{3} \leq$ $\ldots \leq T_{n}, I_{1} \geq I_{2} \geq I_{3} \geq \ldots \geq I_{n}$ and $F_{1} \geq F_{2} \geq F_{3} \geq \ldots \geq F_{n}$.

1) To prove that $T_{1 j}$ is minimum edge truth membership, $I_{1 j}$ is the maximum edge indeterminacy membership and $F_{1 j}$ is the maximum edge falsity membership of $e_{i j}$ emits from $\mathrm{v}_{1} \forall \mathrm{j}=2,3, \ldots, \mathrm{n}$. Assume the contrary i.e. $e_{1 l}$ is not an edge of minimum true membership, maximum indeterminate membership and maximum false membership emits from $v_{l}$. Also let $e_{k l}, 2 \leq \mathrm{k} \leq \mathrm{n}, \mathrm{k} \neq 1$ be an edge with minimum true membership, maximum indeterminate membership and maximum false membership emits from $v_{k}$.

Being a complete SVNG, $\left.F_{l}\right\}$

$T_{1 l}=\min \left\{T_{1}, T_{l}\right\}, I_{1 l}=\max \left\{I_{1}, I_{l}\right\}$ and $F_{1 l}=\max \left\{F_{1}\right.$,

Then $T_{k l}=\min \left\{T_{k}, T_{l}\right\}, I_{k l}=\max \left\{I_{k}, I_{l}\right\}$ and

$F_{k l}=\max \left\{F_{k}, F_{l}\right\}$

Since $T_{k l}<T_{1 l} \Rightarrow \min \left\{T_{k}, T_{l}\right\}<\min \left\{T_{1}, T_{l}\right\}$

Thus either $T_{k}<T_{1}$ or $T_{l}<T_{1}$.

Also since $I_{k l}>I_{1 l} \Rightarrow \max \left\{I_{k}, I_{l}\right\}>\max \left\{I_{1}, I_{l}\right\}$, so either $I_{k}>I_{1}$ or $I_{l}>I_{1}$.

Since $1, k \neq 1$, this is contradiction to our vertex assumption that $T_{1}$ is the unique minimum vertex true membership, $I_{1}$ is the maximum vertex indeterminate membership and $F_{1}$ is the maximum vertex false membership.

Hence $T_{1 j}$ is minimum edge true membership, $I_{1 j}$ is the maximum edge indeterminate membership and $F_{1 j}$ is the maximum edge false membership of $e_{i j}$ emits from $v_{1}$ to $v_{j}$ for all $\mathrm{j}=2,3,4, \ldots, \mathrm{n}$.

2) On the contrary, assume let $e_{k n}$ is not an edge with maximum true membership, minimum indeterminate membership and minimum false membership emits from $v_{k}$ for $1 \leq \mathrm{k} \leq \mathrm{n}-1$. On the other hand, let $e_{k r}$ be an edge with maximum true membership, minimum indeterminate membership and minimum false membership emits from $v_{r}$ from $1 \leq \mathrm{r} \leq \mathrm{n}-1, \mathrm{k} \neq \mathrm{r}$.

Then $T_{k r}>T_{k n} \Rightarrow \min \left\{T_{k}, T_{r}\right\}>\min \left\{T_{k}, T_{n}\right\}=T_{k}$, so $T_{r}>T_{k}$,

$I_{k}$ and 
Similarly $F_{k r}<F_{k n} \Rightarrow \max \left\{F_{k}, F_{r}\right\}<\max \left\{F_{k}, F_{n}\right\}$ $=F_{k}, \Rightarrow F_{r}<F_{k}$

So $T_{k r}=T_{k}=T_{k n}, I_{k r}=I_{k}=I_{k n}$ and $F_{k r}=F_{k}=F_{k n}$, which is a contradiction. Hence $e_{k n}$ is an edge with maximum true membership, minimum indeterminate membership and minimum false membership among all edges emits from $v_{k}$ to $v_{n}$.

3) Now

$\operatorname{td} d_{T}\left(v_{1}\right)=d_{T}\left(v_{1}\right)+T_{1}$

$=\sum_{e_{i j} \in \mathrm{E}} T_{1 j}+T_{1}=\sum_{j=2}^{n} T_{1 j}+T_{1}$

$=(\mathrm{n}-1) \cdot T_{1}+T_{1}=\mathrm{n} T_{1}-T_{1}+T_{1}=\mathrm{n} T_{1}$,

$\mathrm{t} d_{I}\left(v_{1}\right)=d_{I}\left(v_{1}\right)+I_{1}$

$=\sum_{e_{i j} \in \mathrm{E}} I_{1 j}+I_{1}=\sum_{j=2}^{n} I_{1 j}+I_{1}$

$=(\mathrm{n}-1) \cdot I_{1}+I_{1}=\mathrm{n} I_{1}-I_{1}+I_{1}=\mathrm{n} I_{1}$ and

Similarly,

$\operatorname{t} d_{F}\left(v_{1}\right)=d_{F}\left(v_{1}\right)+F_{1}$

$=\sum_{e_{i j} \in \mathrm{E}} F_{1 j}+F_{1}=\sum_{j=2}^{n} F_{1 j}+F_{1}$

$=(\mathrm{n}-1) \cdot F_{1}+F_{1}=\mathrm{n} F_{1}-F_{1}+F_{1}=\mathrm{n} F_{1}$

Suppose that $\mathrm{t}_{T}\left(v_{1}\right) \neq \delta_{\mathrm{t} d_{T}}(\mathrm{G})$ and let $v_{k}, \mathrm{k} \neq 1$ be a vertex in $\mathrm{G}$ with minimum $\mathrm{T}$ - total degree.

Then,

$$
\begin{aligned}
& \mathrm{t}_{T}\left(v_{1}\right)>\mathrm{t} d_{T}\left(v_{k}\right) \\
& \Rightarrow \sum_{i=2}^{n} T_{1 i}+T_{1}>\sum_{k \neq 1, k \neq j} T_{k j}+T_{k} \\
& \Rightarrow \sum_{i=2}^{n} T_{1} \wedge T_{i}+T_{1}>\sum_{k \neq 1, k \neq j} T_{k} \wedge T_{j}+T_{k}
\end{aligned}
$$

Since $T_{1} \wedge T_{i}=T_{1}$ for $\mathrm{i}=1,2,3, \ldots, \mathrm{n}$ and for all other indices $\mathrm{j}, T_{k} \wedge T_{j}>T_{1}$, it follow that

$$
\text { (n - 1). } T_{1}+T_{1}>\sum_{k \neq 1, k \neq j} T_{k} \wedge T_{j}+T_{k}>(\mathrm{n}-1) \cdot T_{1}+T_{1}
$$

Hence, $\operatorname{t} d_{T}\left(v_{1}\right)>\operatorname{t} d_{T}\left(v_{1}\right)$, a contradiction.

Therefore, $\mathrm{t} d_{T}\left(v_{1}\right)=\delta_{\mathrm{t} d_{T}}(\mathrm{G})$.

Suppose that $\mathrm{t}_{I}\left(\mathrm{v}_{1}\right) \neq \Delta_{\mathrm{t} d_{I}}(\mathrm{G})$ and let $v_{k}, \mathrm{k} \neq 1$ be a vertex in $\mathrm{G}$ with maximum I- total degree.

Then,

$$
\begin{aligned}
& \operatorname{td}_{I}\left(v_{1}\right)<\mathrm{t} d_{I}\left(v_{k}\right) \\
& \Rightarrow \sum_{i=2}^{n} I_{1 i}+I_{1}<\sum_{k \neq 1, k \neq j} I_{k j}+I_{k} \\
& \Rightarrow \sum_{i=2}^{n} I_{1} \vee I_{i}+I_{1}<\sum_{k \neq 1, k \neq j} I_{k} \vee I_{j}+I_{k}
\end{aligned}
$$

Since $I_{1} \vee I_{i}=I_{1}$ for $\mathrm{i}=1,2,3, \ldots, \mathrm{n}$ and for all other indices $\mathrm{j}, I_{k} \vee I_{j}<I_{1}$, it follow that

$(\mathrm{n}-1) \cdot I_{1}+I_{1}<\sum_{k \neq 1, k \neq j} I_{k} \vee I_{j}+I_{k}<(\mathrm{n}-1) \cdot I_{1}+I_{1}$

So that $\mathrm{t} d_{I}\left(v_{1}\right)<\mathrm{t} d_{I}\left(v_{1}\right)$, a contradiction.

Therefore, $\mathrm{t} d_{I}\left(v_{1}\right)=\Delta_{\mathrm{t} d_{I}}(\mathrm{G})$.

Also, Suppose that $\mathrm{t}_{F}\left(\mathrm{v}_{1}\right) \neq \Delta_{\mathrm{t} d_{F}}(\mathrm{G})$ and let $v_{k}, \mathrm{k} \neq 1$ be a vertex in $\mathrm{G}$ with maximum $\mathrm{F}$ - total degree.

Then

$$
\begin{aligned}
& \operatorname{td} F\left(v_{1}\right)<\operatorname{td} F\left(v_{k}\right) \\
& \Rightarrow \sum_{i=2}^{n} F_{1 i}+F_{1}<\sum_{k \neq 1, k \neq j} F_{k j}+F_{k} \\
& \Rightarrow \sum_{i=2}^{n} F_{1} \vee F_{i}+F_{1}<\sum_{k \neq 1, k \neq j} F_{k} \vee F_{j}+F_{k}
\end{aligned}
$$

Since $F_{1} \vee F_{i}=F_{1}$ for $\mathrm{i}=1,2,3, \ldots, \mathrm{n}$ and for all other indices $\mathrm{j}, F_{k} \vee F_{j}<F_{1}$, it follow that

$(\mathrm{n}-1) \cdot F_{1}+F_{1}<\sum_{k \neq 1, k \neq j} F_{k} \vee F_{j}+F_{k}<(\mathrm{n}-1) \cdot F_{1}+F_{1}$

So that $\operatorname{td} d_{F}\left(v_{1}\right)<\operatorname{td} d_{F}\left(v_{1}\right)$, a contradiction .

Therefore, $\operatorname{t} d_{F}\left(v_{1}\right)=\Delta_{\mathrm{t} d_{F}}(\mathrm{G})$.

Hence,

$$
\begin{aligned}
& \mathrm{t} d_{T}\left(\mathrm{v}_{1}\right)=\delta_{\mathrm{t} d_{T}}(\mathrm{G})=\mathrm{n} \cdot \mathrm{T}_{1}, \\
& \mathrm{t} d_{I}\left(\mathrm{v}_{1}\right)=\Delta_{\mathrm{t} d_{I}}(\mathrm{G})=\mathrm{n} \cdot \mathrm{I}_{1} \text { and } \\
& \mathrm{t} d_{F}\left(\mathrm{v}_{1}\right)=\Delta_{\mathrm{t} d_{F}}(\mathrm{G})=\mathrm{n} \cdot \mathrm{F}_{1} .
\end{aligned}
$$

4) Since, $T_{n}>T_{i}, I_{n}<I_{i}$ and $F_{n}<F_{i}, \mathrm{i}=1,2,3, \ldots, \mathrm{n}-1$ and $\mathrm{G}$ is complete

$T_{n i}=T_{n} \wedge T_{i}=T_{i}, I_{n i}=I_{n} \vee I_{i}=I_{i}$ and $F_{n i}=F_{n} \vee F_{i}=F_{i}$.

Hence, $\operatorname{t} d_{T}\left(v_{n}\right)=\sum_{i=1}^{n-1} T_{n i}+T_{n}$

$=\sum_{i=1}^{n-1}\left(T_{n} \wedge \mathrm{T}_{\mathrm{i}}\right)+T_{n}=\sum_{i=1}^{n-1} T_{i}+T_{n}$

$=\sum_{i=1}^{n} T_{i}$,

$\operatorname{t} d_{I}\left(v_{n}\right)=\sum_{i=1}^{n-1} I_{n i}+I_{n}$

$=\sum_{i=1}^{n-1}\left(I_{n} \vee \mathrm{I}_{\mathrm{i}}\right)+I_{n}=\sum_{i=1}^{n-1} I_{i}+I_{n}$

$=\sum_{i=1}^{n} I_{i}$

And $\mathrm{t} d_{F}\left(v_{n}\right)=\sum_{i=1}^{n-1} F_{n i}+F_{n}$

$=\sum_{i=1}^{n-1}\left(F_{n} \vee \mathrm{F}_{\mathrm{i}}\right)+F_{n}=\sum_{i=1}^{n-1} F_{i}+F_{n}$

$=\sum_{i=1}^{n} F_{i}$.

Suppose that $\mathrm{t}_{T}\left(v_{n}\right) \neq \Delta_{\mathrm{t} d_{T}}(\mathrm{G})$. Let $v_{l}, 1 \leq 1 \leq \mathrm{n}-1$ be a vertex in $\mathrm{G}$ such that $\mathrm{t} d_{T}\left(v_{l}\right)=\Delta_{\mathrm{t} d_{T}}(\mathrm{G})$ and

$\mathrm{t} d_{T}\left(v_{n}\right)<\mathrm{t} d_{T}\left(v_{l}\right)$. In addition,

$\mathrm{t} d_{T}\left(v_{l}\right)=\left[\sum_{i=1}^{l-1} T_{i l}+\sum_{i=l+1}^{n-1} T_{i l}+T_{n l}\right]+T_{l}$ 


$$
\begin{aligned}
& \leq\left[\sum_{i=1}^{l-1} T_{i}+(\mathrm{n}-1) T_{l}+T_{l}\right]+T_{l} \\
& \leq \sum_{i=1}^{n-1} T_{i}+T_{l} \\
& \leq \sum_{i=1}^{n} T_{i}=\mathrm{t} d_{T}\left(v_{n}\right) . \text { Thus } \mathrm{t} d_{T}\left(v_{n}\right) \geq \mathrm{t} d_{T}\left(v_{l}\right),
\end{aligned}
$$
contradiction. So, $\operatorname{t} d_{T}\left(v_{n}\right)=\Delta_{\mathrm{t} d_{T}}(\mathrm{G})=\sum_{i=1}^{n} T_{i}$.

Suppose that $\operatorname{t} d_{I}\left(v_{n}\right) \neq \delta_{\mathrm{t} d_{I}}(\mathrm{G})$. Let $v_{l}, 1 \leq 1 \leq \mathrm{n}-1$ be a vertex in $\mathrm{G}$ such that $\mathrm{t} d_{I}\left(v_{l}\right)=\delta_{\mathrm{t} d_{I}}(\mathrm{G})$ and $\left.\mathrm{t} d_{I}\left(v_{n}\right)>\mathrm{t} d_{I} v_{l}\right)$.

In addition,

$$
\begin{aligned}
& \mathrm{t}_{I}\left(v_{l}\right)=\left[\sum_{i=1}^{l-1} I_{i l}+\sum_{i=l+1}^{n-1} I_{i l}+I_{n l}\right]+I_{l} \\
& \geq\left[\sum_{i=1}^{l-1} I_{i}+(\mathrm{n}-1) I_{l}+I_{l}\right]+I_{l} \\
& \geq \sum_{i=1}^{n-1} I_{i}+I_{l} \\
& \geq \sum_{i=1}^{n} I_{i}=\mathrm{t} d_{I}\left(v_{n}\right) . \text { Thus } \mathrm{t} d_{I}\left(v_{n}\right) \leq \mathrm{t} d_{I}\left(v_{l}\right), \text { contradiction. }
\end{aligned}
$$
So, $\operatorname{td} d_{I}\left(v_{n}\right)=\delta_{\mathrm{t} d_{I}}(\mathrm{G})=\sum_{i=1}^{n} I_{i}$.

Also, suppose that $\mathrm{t}_{F}\left(v_{n}\right) \neq \delta_{\mathrm{t} d_{F}}(\mathrm{G})$. Let $v_{l}, 1 \leq 1 \leq \mathrm{n}-1$ be a vertex in G such that $\mathrm{t}_{F}\left(v_{l}\right)=\delta_{\mathrm{t} d_{F}}(\mathrm{G})$ and $\mathrm{t} d_{F}\left(v_{n}\right)>$ $\left.\operatorname{t} d_{F} v_{l}\right)$. In addition,

$$
\begin{aligned}
& \mathrm{t} d_{F}\left(v_{l}\right)=\left[\sum_{i=1}^{l-1} F_{i l}+\sum_{i=l+1}^{n-1} F_{i l}+F_{n l}\right]+F_{l} \\
& \geq\left[\sum_{i=1}^{l-1} F_{i}+(\mathrm{n}-1) F_{l}+F_{l}\right]+F_{l} \\
& \geq \sum_{i=1}^{n-1} F_{i}+F_{l} \\
& \geq \sum_{i=1}^{n} F_{i}=\mathrm{t} d_{F}\left(v_{n}\right) . \text { Thus } t d_{F}\left(v_{n}\right) \leq \mathrm{t} d_{F}\left(v_{l}\right),
\end{aligned}
$$
contradiction. So, $t d_{F}\left(v_{n}\right)=\delta_{\mathrm{t} d_{F}}(\mathrm{G})=\sum_{i=1}^{n} F_{i}$.

Hence the lemma is proved.

Remark 3.32 In a complete SVNG G,

1) There exists at least one pair of vertices $v_{i}$ and $v_{j}$ such that $d_{T_{i}}=d_{T_{j}}=\Delta_{T}(\mathrm{G}), d_{I_{i}}=d_{I_{i}}=\delta_{I}(\mathrm{G})$ and $d_{F_{i}}=d_{F_{i}}=\delta_{F}(\mathrm{G})$,

2) $\operatorname{td} d_{T}\left(v_{i}\right)=O_{T}(G)=\Delta_{t d_{T}}(G), \quad \operatorname{td} d_{I}\left(v_{i}\right)=O_{I}(G)=\delta_{\mathrm{t} d_{I}}(\mathrm{G})$ and $t d_{F}\left(v_{i}\right)=O_{F}(\mathrm{G})=\delta_{\mathrm{t} d_{F}}(\mathrm{G})$ for a vertex $v_{i} \in \mathrm{V}$,

3) $\sum_{i=1}^{n} t d_{T}\left(v_{i}\right)=2 S_{T}(\mathrm{G})+O_{T}(\mathrm{G}), \sum_{i=1}^{n} \mathrm{t} d_{I}\left(v_{i}\right)=$ $2 S_{I}(G)+O_{I}(G)$ and $\sum_{i=1}^{n} \mathrm{t} d_{F}\left(v_{i}\right)=2 S_{F}(\mathrm{G})+O_{F}(\mathrm{G})$.

IV. VERTEX TRUth MEMBERSHIP, VERTEX INDTERMINACY MEMBERSHIP AND VERTEX FALSITY MEMEBERSHIP SEQUENCE IN SVNG

In this section, vertex truth membership, vertex indeterminacy membership and vertex falsity membership sequences are defined in SVNGs.

Definition 4.1 Given a SVN-graph $\mathrm{G}$ with $|V|=\mathrm{n}$. The vertex truth membership sequence of $\mathrm{G}$ is defined to be $\left\{x_{i}\right\}_{i=1}^{n}$ with $x_{1} \leq x_{2} \leq x_{3} \leq \ldots \leq x_{n}$ where $x_{i}, 0<x_{i} \leq 1$, is the truth membership value of the vertex $v_{i}$ when vertices are arranged so that their truth membership values are nondecreasing.

Particular, $x_{1}$ is smallest vertex truth membership value and $x_{n}$ is largest vertex truth membership value in $\mathrm{G}$.

Note 4.2 If vertex truth membership sequence $x_{i}$ is repeated more than once in $\mathrm{G}$, say $\mathrm{r} \neq 1$ times, then it is denoted by $x_{i}^{r}$ in the sequence.
Example 4.3 In Fig. 2 the vertex truth membership sequence of $\mathrm{G}$ is $\{0.1,0.1,0.3,0.3,0.4,0.8\}$ or $\left\{0.1^{2}, 0.3^{2}\right.$, $0.4,0.8\}$.

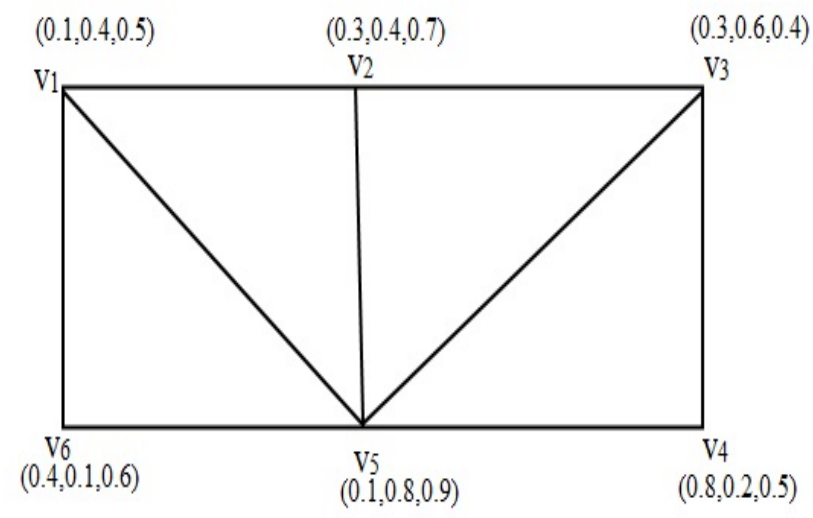

Fig. 2. Vertex truth membership sequence.

Definition 4.4 Let $G$ be a SVNG with $|V|=n$. The vertex indeterminacy membership sequence of $\mathrm{G}$ is defined to be $\left\{y_{i}\right\}_{i=1}^{n}$ with $y_{1} \leq y_{2} \leq y_{3} \leq \ldots \leq y_{n}$ where $y_{i}, 0<y_{i} \leq 1$, is the indeterminacy membership value of the vertex $v_{i}$ when vertices are arranged so that their indeterminacy membership values are non- increasing.

Particular, $y_{1}$ is largest vertex indeterminacy membership value and $y_{n}$ is smallest vertex indeterminacy membership value in $\mathrm{G}$.

Note 4.5 If vertex indeterminacy membership sequence $y_{i}$ is repeated more than once in $G$, say $r \neq 1$ times, then it is denoted by $y_{i}^{r}$ in the sequence.

Example 4.6 In Fig. 3 the vertex indeterminacy membership sequence of $\mathrm{G}$ is $\{0.7,0.6,0.6,0.5,0.4,0.4\}$ or \{ $\left.0.7,0.6^{2}, 0.5,0.4^{2}\right\}$.

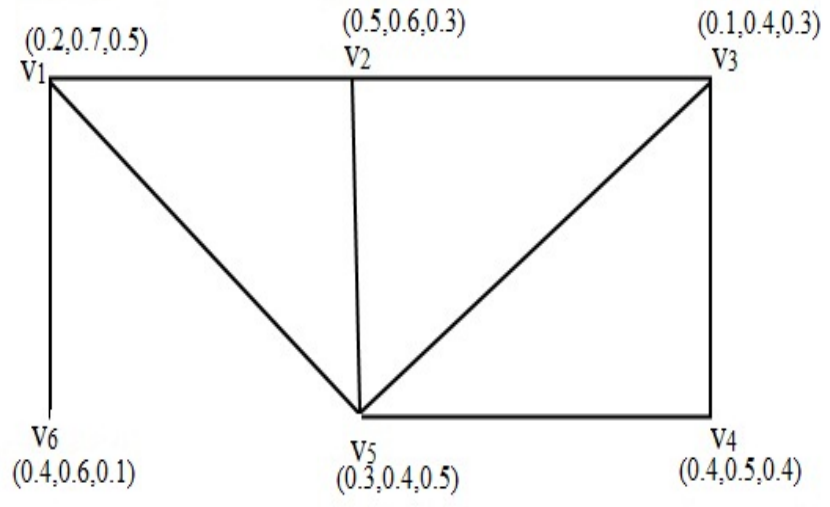

Fig. 3. Vertex indeterminacy membership sequence.

Definition 4.7 Let $\mathrm{G}$ be a SVNG with $|V|=\mathrm{n}$. The vertex falsity membership sequence of $\mathrm{G}$ is defined to be $\left\{z_{i}\right\}_{i=1}^{n}$ with $z_{1} \leq z_{2} \leq z_{3} \leq \ldots \leq z_{n}$ where $z_{i}, 0<z_{i} \leq 1$, is the falsity membership value of the vertex $v_{i}$ when vertices are arranged so that their falsity membership values are non- increasing. Particular, $z_{1}$ is largest vertex falsi $\mathrm{Y}$ membership value and $z_{n}$ is smallest vertex falsity membership value in $\mathrm{G}$. 
Note 4.8 If vertex falsity membership sequence $z_{i}$ is repeated more than once in $G$, say $r \neq 1$ times, then it is denoted by $z_{i}^{r}$ in the sequence.

Example 4.9 In Fig. 4 the vertex falsity membership sequence of $\mathrm{G}$ is $\{0.8,0.8,0.7,0.6,0.6,0.5\}$ or $\left\{0.8^{2}\right.$, $\left.0.7,0.6^{2}, 0.5\right\}$.

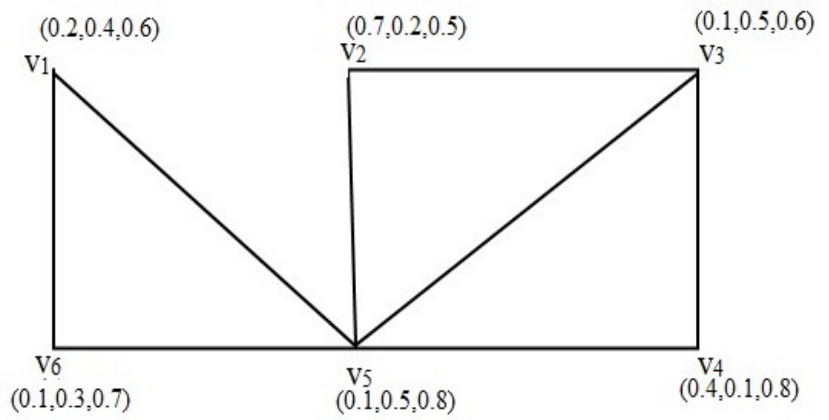

Fig. 4. Vertex falsity membership sequence.

Definition 4.10 If a SVNG with $|V|=\mathrm{n}$ has vertex truth membership sequence $\left\{x_{i}\right\}_{i=1}^{n}$, vertex indeterminacy membership sequence $\left\{y_{i}\right\}_{i=1}^{n}$ and vertex falsity membership sequence $\left\{z_{i}\right\}_{i=1}^{n}$ in same order, then it said to have vertex single valued neutrosophic sequence and denoted by $\{<$ $\left.x_{i}, y_{i}, z_{i}>\right\}_{i=1}^{n}$.

Example 4.11 In Fig. 5 the vertex truth membership, vertex indeterminacy membership and vertex falsity membership sequence of $\mathrm{G}$ is $\{<0.4,0.4,0.5>,<0.2,0.3,0.5\rangle$, $<$ $0.1,0.2,0.6>,<0.5,0.4,0.8>,<0.4,0.5,0.4>,<0.3,0.1,0.7>\}$.

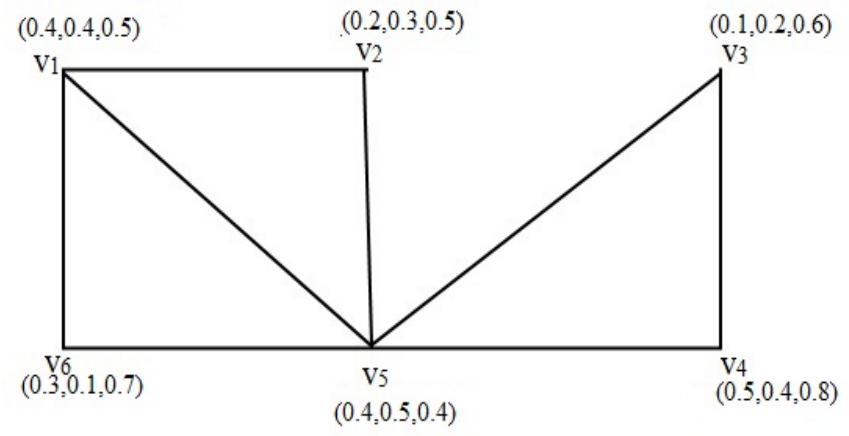

Fig. 5. Vertex single valued neutrosophic sequence.

The properties of vertex truth membership, vertex indeterminacy membership and vertex falsity sequences of complete SVNGs are discussed below:

Theorem 4.12 Let $\mathrm{G}=(\mathrm{V}, \mathrm{E})$ be a complete $\mathrm{SVNG}$ with $|V|$ $=\mathrm{n}$. Then

1) If the vertex truth membership sequence of $\mathrm{G}$ is of the form $\left\{x_{1}{ }^{n-1}, x_{2}\right\}$, vertex indeterminacy membership sequence of $\mathrm{G}$ is of the form $\left\{y_{1}{ }^{n-1}, y_{2}\right\}$ and vertex falsity membership sequence of $\mathrm{G}$ is of the form $\left\{z_{1}{ }^{n-1}, z_{2}\right\}$, then

$$
\begin{aligned}
& \text { a. } \delta_{\mathrm{t} d_{T}}(\mathrm{G})=\text { n. } T_{1} \text { and } \Delta_{\mathrm{t} d_{T}}(\mathrm{G})=\sum_{i=1}^{n} T_{i} \\
& \text { b. } \Delta_{\mathrm{t} d_{I}}(\mathrm{G})=\text { n. } I_{1} \text { and } \delta_{\mathrm{t} d_{I}}(\mathrm{G})=\sum_{i=1}^{n} I_{i}
\end{aligned}
$$

$$
\text { c. } \Delta_{\mathrm{t} d_{F}}(\mathrm{G})=\mathrm{n} \cdot F_{1} \text { and } \delta_{\mathrm{t} d_{F}}(\mathrm{G})=\sum_{i=1}^{n} F_{i}
$$

2) If the vertex truth membership sequence of $\mathrm{G}$ is of the form $\left\{x_{1}{ }^{r_{1}}, x_{2}{ }^{n-r_{1}}\right\}$, vertex indeterminacy membership of $\mathrm{G}$ is of the form $\left\{y_{1}{ }^{r_{1}}, y_{2}{ }^{n-r_{1}}\right\}$ and vertex falsity membership sequence of $\mathrm{G}$ is of the form $\left\{z_{1}{ }^{r_{1}}, z_{2}{ }^{n-r_{1}}\right\}$ with $0<r_{1} \leq \mathrm{n}-2$, then there exists exactly $r_{1}$ vertices with minimum T- total degree $\delta_{\mathrm{t} d_{T}}(\mathrm{G})$, maximum I-total degree $\Delta_{t d_{I}}(G)$ and maximum F-total degree $\Delta_{t d_{F}}$ and exactly (n- $\left.r_{1}\right)$ vertices with maximum T- total degree $\Delta_{\mathrm{t} d_{T}}(\mathrm{G})$, minimum I- total degree $\delta_{\mathrm{t} d_{I}}(\mathrm{G})$ and minimum F- total degree $\delta_{\mathrm{t} d_{F}}(\mathrm{G})$.

3) If the vertex truth membership sequence of $\mathrm{G}$ is of the form $\left\{x_{1}{ }^{r_{1}}, x_{2}{ }^{r_{2}}, x_{3}{ }^{r_{3}}, \ldots, x_{k}{ }^{r_{k}}\right\}$, vertex indeterminacy membership sequence of $\mathrm{G}$ is of the form $\left\{y_{1}{ }^{r_{1}}, y_{2}{ }^{r_{2}}, y_{3}{ }^{r_{3}}, \ldots\right.$ ., $y_{k}{ }^{r_{k}}$ and vertex falsity membership sequence of $\mathrm{G}$ is of the form $\left\{z_{1}{ }^{r_{1}}, z_{2}{ }^{r_{2}}, z_{3}{ }^{r_{3}}, \ldots, z_{k}{ }^{r_{k}}\right\}$ with $r_{k}>1$ and $\mathrm{k}>2$, then there exists exactly $r_{1}$ vertices with minimum T- total degree $\delta_{\mathrm{t} d_{T}}(\mathrm{G})$, maximum I- total degree $\Delta_{t d_{I}}$ and maximum F-total degree $\Delta_{t d_{F}}$. Also, there exists exactly $r_{k}$ vertices with maximum T- total degree $\Delta_{\mathrm{t} d_{T}}(\mathrm{G})$, minimum I- total degree $\delta_{\mathrm{t} d_{I}}(\mathrm{G})$ and minimum F- total degree $\delta_{\mathrm{t} d_{F}}(\mathrm{G})$.

Proof: The proof of (1) and (2) are obvious. 3 Let $v_{i}^{(j)}$ be the set of vertices in $\mathrm{G}$, for $\mathrm{j}=1,2,3, \ldots, r_{i}, 1 \leq \mathrm{i} \leq \mathrm{k}$. Then by the Theorem3.31

$$
\begin{aligned}
& t d_{T}\left(v_{1}^{(j)}\right)=\delta_{t d_{T}}(G)=\text { n. } T_{1}=\text { n. } x_{1}, \\
& t d_{I}\left(v_{1}^{(j)}\right)=\Delta_{t d_{I}}(G)=\text { n. } I_{1}=\text { n. } y_{1}, \text { and } \\
& t d_{F}\left(v_{1}^{(j)}\right)=\delta_{t d_{F}}(G)=\text { n. } F_{1}=\text { n. } z_{1},, \text { for } \mathrm{j}=1,2,3, \ldots, r_{1} .
\end{aligned}
$$

Since $\mathrm{T}\left(v_{i}^{(j)}, v_{i+1}^{(l)}\right)=\mathrm{T}\left(v_{i}^{(j)}\right)>x_{1}$ for $2 \leq \mathrm{i} \leq \mathrm{k}, \mathrm{j}=1,2,3$, $\ldots, r_{i}, 1=1,2,3, \ldots, r_{i+1}$, no vertex with truth membership more than $x_{1}$ can have degree $\delta_{\mathrm{t} d_{T}}(\mathrm{G})$,

$$
\mathrm{I}\left(v_{i}^{(j)}, v_{i+1}^{(l)}\right)=\mathrm{I}\left(v_{i}^{(j)}\right)<y_{1} \text { for } 2 \leq \mathrm{i} \leq \mathrm{k}, \mathrm{j}=1,2,3, \ldots,
$$
$r_{i}, 1=1,2,3, \ldots, r_{i+1}$, no vertex with indeterminacy membership less than $y_{1}$ can have degree $\Delta_{\mathrm{t} d_{I}}(\mathrm{G})$

And $\mathrm{F}\left(v_{i}^{(j)}, v_{i+1}^{(l)}\right)=\mathrm{F}\left(v_{i}^{(j)}\right)<z_{1}$ for $2 \leq \mathrm{i} \leq \mathrm{k}, \mathrm{j}=1,2,3$, $\ldots, r_{i}, 1=1,2,3, \ldots, r_{i+1}$, no vertex with falsity membership less than $z_{1}$ can have degree $\Delta_{\mathrm{t} d_{F}}(\mathrm{G})$.

Thus, there exist exactly $r_{1}$ vertices with degree $\delta_{\mathrm{t} d_{T}}(\mathrm{G})$, $\Delta_{\mathrm{t} d_{I}}(\mathrm{G}), \Delta_{\mathrm{t} d_{F}}(\mathrm{G})$.

To prove $t d_{T}\left(v_{k}^{(t)}\right)=\Delta_{t d_{T}}(G)$,

$$
\begin{aligned}
& \mathrm{t} d_{I}\left(v_{k}^{(t)}\right)=\delta_{\mathrm{t} d_{I}}(\mathrm{G}) \text { and } \\
& t d_{F}\left(v_{k}^{(t)}\right)=\delta_{\mathrm{t} d_{F}}(\mathrm{G}), \mathrm{t}=1,2,3 \ldots, r_{k} .
\end{aligned}
$$

Since, $\mathrm{T}\left(v_{k}^{(t)}\right)$ is maximum vertex truth membership,

$$
\begin{aligned}
& \mathrm{T}\left(v_{k}^{(t)}, v_{k}^{(j)}\right)=x_{k}, \mathrm{t} \neq \mathrm{j}, \mathrm{t}, \mathrm{j}=1,2,3, \ldots, r_{k} \\
& \mathrm{~T}\left(v_{k}^{(t)}, v_{i}^{(j)}\right)=\min \left\{\mathrm{T}\left(v_{k}^{(t)}\right), \mathrm{T}\left(v_{i}^{(j)}\right)\right\}=\mathrm{T}\left(v_{i}^{(j)}\right) \text { for } \mathrm{t}= \\
& 1,2,3 \ldots, r_{k}, \mathrm{j}=1,2,3, \ldots, r_{i}, \mathrm{i}=1,2,3, \ldots, \mathrm{k}-1
\end{aligned}
$$


Thus for $\mathrm{t}=1,2,3, \ldots, r_{k}$,

$t d_{T}\left(v_{k}^{(t)}\right)=\sum_{i=1}^{k} \sum_{j=1}^{r_{i}} \mathrm{~T}\left(v_{i}^{(j)}\right)+\left(r_{k}-1\right) x_{k}$

$=\sum_{i=1}^{n} T_{i}$

\section{$=\Delta_{\mathrm{t} d_{T}}(\mathrm{G})$ by Theorem 3.31}

Now, if $v_{m}$ is vertex such that $T_{m}=x_{k-1}$, then

$\mathrm{t} d_{T}\left(v_{m}\right)=\sum_{i=1}^{k-2} \sum_{j=1}^{r_{i}} \mathrm{~T}\left(v_{m}, v_{i}^{(j)}\right)+\left(r_{k-1}-1+r_{k}\right) x_{k-1}+T_{m}$

$=\sum_{i=1}^{k-2} \sum_{j=1}^{r_{i}} \mathrm{~T}\left(v_{i}^{(j)}\right)+\sum_{j=1}^{r_{k-1}} \mathrm{~T}\left(v_{k-1}^{(j)}\right)+\left(r_{k}-1\right) x_{k-1}+T_{m}$

$<\sum_{i=1}^{k-2} \sum_{j=1}^{r_{i}} \mathrm{~T}\left(v_{i}^{(j)}\right)+\sum_{j=1}^{r_{k-1}} \mathrm{~T}\left(v_{k-1}^{(j)}\right)+\left(r_{k}-1\right) x_{k}+T_{m}$

$=\Delta_{\mathrm{t} d_{T}}(\mathrm{G})$

Thus, there exist exactly $r_{k}$ vertices with degree $\Delta_{\mathrm{t} d_{T}}(\mathrm{G})$.

To prove $\mathrm{t} d_{I}\left(v_{k}^{(t)}\right)=\delta_{\mathrm{t} d_{I}}(\mathrm{G})$, for $\mathrm{t}=1,2,3, \ldots, r_{k}$

Since $\mathrm{I}\left(v_{k}^{(t)}\right)$ is minimum vertex indeterminacy membership,

$$
\begin{aligned}
& \mathrm{I}\left(v_{k}^{(t)}, v_{k}^{(j)}\right)=y_{k}, \mathrm{t} \neq \mathrm{j}, \mathrm{t}, \mathrm{j}=1,2,3, \ldots, r_{k} \\
& \mathrm{I}\left(v_{k}^{(t)}, v_{i}^{(j)}\right)=\max \left\{\mathrm{I}\left(v_{k}^{(t)}\right), \mathrm{I}\left(v_{i}^{(j)}\right)\right\}=\mathrm{I}\left(v_{i}^{(j)}\right) \text { for } \mathrm{t}=1,2,3, \\
& \ldots, r_{k}, \mathrm{j}=1,2,3, \ldots, r_{i}, \\
& \mathrm{i}=1,2,3, \ldots, \mathrm{k}-1 . \\
& \\
& \text { Thus for } \mathrm{t}=1,2,3, \ldots, r_{k}, \\
& \mathrm{t} d_{I}\left(v_{k}^{(t)}\right)=\sum_{i=1}^{k} \sum_{j=1}^{r_{i}} \mathrm{I}\left(v_{i}^{(j)}\right)+\left(r_{k}-1\right) y_{k} \\
&=\sum_{i=1}^{n} I_{i} \\
&=\delta_{\mathrm{t} d_{I}}(\mathrm{G}) \text { by Theorem } 3.31 \\
& \mathrm{Now}, \mathrm{if} v_{m} \text { is vertex such that } I_{m}=y_{k-1}, \text { then } \\
& \mathrm{t} d_{I}\left(v_{m}\right)=\sum_{i=1}^{k-2} \sum_{j=1}^{r_{i}} \mathrm{I}\left(v_{m}, v_{i}^{(j)}\right)+\left(r_{k-1}-1+r_{k}\right) y_{k-1}+I_{m} \\
&=\sum_{i=1}^{k-2} \sum_{j=1}^{r_{i}} \mathrm{I}\left(v_{i}^{(j)}\right)+\sum_{j=1}^{r_{k-1}} \mathrm{I}\left(v_{k-1}^{(j)}\right)+\left(r_{k}-1\right) y_{k-1}+I_{m} \\
&<\sum_{i=1}^{k-2} \sum_{j=1}^{r_{i}} \mathrm{I}\left(v_{i}^{(j)}\right)+\sum_{j=1}^{r_{k-1}} \mathrm{I}\left(v_{k-1}^{(j)}\right)+\left(r_{k}-1\right) y_{k}+I_{m} \\
&=\delta_{\mathrm{t} d_{I}}(\mathrm{G})
\end{aligned}
$$

So, there exist exactly $r_{k}$ vertices with degree $\delta_{\mathrm{t} d_{I}}(\mathrm{G})$.

Similarly, it can be proved that $\mathrm{t} d_{F}\left(v_{k}^{(t)}\right)=\delta_{\mathrm{t} d_{F}}(\mathrm{G})$, for $\mathrm{t}=$ $1,2,3, \ldots, r_{k}$

Since $\mathrm{F}\left(v_{k}^{(t)}\right)$ is minimum vertex falsity membership,

$\mathrm{F}\left(v_{k}^{(t)}, v_{k}^{(j)}\right)=z_{k}, \mathrm{t} \neq \mathrm{j}, \mathrm{t}, \mathrm{j}=1,2,3, \ldots, r_{k}$

$\mathrm{F}\left(v_{k}^{(t)}, v_{i}^{(j)}\right)=\max \left\{\mathrm{F}\left(v_{k}^{(t)}\right), \mathrm{F}\left(v_{i}^{(j)}\right)\right\}=\mathrm{F}\left(v_{i}^{(j)}\right)$ for $\mathrm{t}=1,2$, $3, \ldots, r_{k}, \mathrm{j}=1,2,3, \ldots, r_{i}, \mathrm{i}=1,2,3, \ldots, \mathrm{k}-1$.

Thus for $\mathrm{t}=1,2,3, \ldots, r_{k}$,

$$
\mathrm{t} d_{F}\left(v_{k}^{(t)}\right)=\sum_{i=1}^{k} \sum_{j=1}^{r_{i}} \mathrm{~F}\left(v_{i}^{(j)}\right)+\left(r_{k}-1\right) z_{k}
$$

$=\sum_{i=1}^{n} F_{i}$

$=\delta_{\mathrm{t} d_{F}}(\mathrm{G})$ by Theorem 3.31

Now, if $v_{m}$ is vertex such that $F_{m}=z_{k-1}$, then

$$
\begin{aligned}
& \operatorname{t} d_{F}\left(v_{m}\right)=\sum_{i=1}^{k-2} \sum_{j=1}^{r_{i}} \mathrm{~F}\left(v_{m}, v_{i}^{(j)}\right)+\left(r_{k-1}-1+r_{k}\right) F_{k-1}+F_{m} \\
& =\sum_{i=1}^{k-2} \sum_{j=1}^{r_{i}} \mathrm{~F}\left(v_{i}^{(j)}\right)+\sum_{j=1}^{r_{k-1}} \mathrm{~F}\left(v_{k-1}^{(j)}\right)+\left(r_{k}-1\right) z_{k-1}+ \\
& <\sum_{i=1}^{k-2} \sum_{j=1}^{r_{i}} \mathrm{~F}\left(v_{i}^{(j)}\right)+\sum_{j=1}^{r_{k-1}} \mathrm{~F}\left(v_{k-1}^{(j)}\right)+\left(r_{k}-1\right) z_{k}+F_{m} \\
& =\delta_{\mathrm{t} d_{F}}(\mathrm{G})
\end{aligned}
$$$$
F_{m}
$$

So, there exist exactly $r_{k}$ vertices with degree $\delta_{\mathrm{t} d_{F}}(\mathrm{G})$.

\section{CONCLUSION}

In this paper, the idea of strong degree is imposed on the existing concepts of degrees in SVNGs. After that, we defined the vertex truth-membership, vertex indeterminacymembership and vertex falsity membership sequence in SVNG with proofs and suitable examples. In the next research, the proposed concepts can be extended to labeling neutrosophic graph and also characterize the corresponding properties.

\section{ACKNOLEDGEMENT}

The authors are very grateful to the chief editor and reviewers for their comments and suggestions, which is helpful in improving the paper.

\section{REFERENCE}

[1] F. Smarandache, "Neutrosophy. Neutrosophic Probability, Set, and Logic," ProQuest Information \& Learning, Ann Arbor, Michigan, USA, 105 p., 199

[2] K. Atanassov, "Intuitionistic fuzzy sets: theory and applications", Physica, New York, 1999.

[3] F. Smarandache, "A unifying field in logic. Neutrosophy: Neutrosophic probability, set, logic," American Research Press, Rehoboth, fourth edition, 2005.

[4] L. Zadeh, "Fuzzy logic and approximate reasoning," Synthese, vol. 30, no. $3-4,1975$, pp. 407-428

[5] L. Zadeh, "Fuzzy Sets," Information and Control, 8, 1965, pp.338-353.

[6] K. Atanassov, "Intuitionistic Fuzzy Sets," Fuzzy Sets and Systems, Vol.20, 1986, pp.87-96.

[7] H. Wang, F. Smarandache, Y. Zhang and R.Sunderraman, "Single Valued Neutrosophic Sets," Multispace and Multisrtucture 4, 2010, pp.410-413.

[8] http://fs.gallup.unm.edu/NSS.

[9] S. Broumi, M. Talea, A. Bakali, F. Smarandache, "Single Valued Neutrosophic Graphs," Journal of New Theory, N 10, 2016, pp. 86-101.

[10] S. Broumi, M. Talea, A. Bakali, F. Smarandache, "On Bipolar Single Valued Neutrosophic Graphs," Journal of New Theory, N11, 2016, pp.84-102.

[11] S. Broumi, A. Bakali, M, Talea, and F, Smarandache, "Isolated Single Valued Neutrosophic Graphs,"Neutrosophic Sets and Systems, Vol. 11, 2016, pp.74-78

[12] S. Broumi, F. Smarandache, M. Talea and A. Bakali, "An Introduction to Bipolar Single Valued Neutrosophic Graph Theory," Applied Mechanics and Materials, vol.841, 2016, pp. 184-191.

[13] S. Broumi, F. Smarandache, M. Talea and A. Bakali," Decision-Making Method Based On the Interval Valued Neutrosophic Graph," Future technologie, 2016, IEEE, pp.44-50.

[14] S. Broumi, M. Talea, F. Smarandache and A. Bakali," Single Valued 
Neutrosophic Graphs: Degree, Order and Size," IEEE World Congress on Computational Intelligence, 2016, pp.2444-2451.

[15] S. Broumi, A. Bakali, M. Talea and F. Smarandache," Shortest Path Problem under Trapezoidal Neutrosophic Information," Computing Conference 2017, 18-20 July 2017, pp142-148.

[16] S. Broumi, A. Bakali, M. Talea, F. Smarandache and L. Vladareanu, "Computation of Shortest path Problem in a Network with SVTrapezoidal Neutrosophic numbers," Proceedings of the 2016 International Conference on Advanced Mechatronic Systems, Melbourne, Australia, 2016 , pp.417-422.

[17] S. Broumi, A. Bakali, M. Talea, F. Smarandache and L. Vladareanu," Applying Dijkstra Algorithm for Solving Neutrosophic Shortest Path Problem," Proceedings of the 2016 International Conference on Advanced Mechatronic Systems, Melbourne, Australia, 2016, pp.412416.

[18] S. Broumi, M. Talea, A. Bakali, F. Smarandache, "Interval Valued Interval Valued Neutrosophic Graphs," Critical Review, XII, 2016. pp.5-33.

[19] S. Broumi, A. Bakali, T. Mohamed, F. Smarandache and L. Vladareanu," Shortest Path Problem Under Triangular Fuzzy Neutrosophic Information," 10th International Conference on Software, Knowledge, Information Management \& Applications (SKIMA),2016,pp.169-174.

[20] S. Broumi, F. Smarandache, M. Talea and A. Bakali," Operations on Interval Valued Neutrosophic Graphs," chapter in book- New Trends in Neutrosophic Theory and Applications- Florentin Smarandache and SurpatiPramanik (Editors), 2016, pp. 231-254. ISBN 978-1-59973-498-9

[21] S. Broumi, A. Bakali, M. Talea, F. Smarandache and M. Ali, "Shortest Path Problem under Bipolar Neutrosphic Setting," Applied Mechanics and Materials, Vol. 859, 2016, pp. 59-66

[22] S. Ashraf, S. Naz, H. Rashmanlou, and M. A. Malik, "Regularity of graphs in single valued neutrosophic environment," Journal of Intelligent \& Fuzzy Systems, vol 33,no.1,2017,pp.529-542.
[23] S. Naz, H. Rashmanlou, and M. A. Malik," Operations on single valued neutrosophic graphs with application," Journal of Intelligent \& Fuzzy Systems, vol 32,no.3,2017,pp.2137-2151.

[24] S. Mehra and Manjeet Singh, "Single Valued Neutrosophic Signed graphs ," International Journal of Computer Applications, Volume 157 No 9, 2017 ,pp.32-34.

[25] M. Hamidi and A. Bourumand Saeid," Accessible single valued neutrosophic graphs,"J.Appl.Math.Comput,2017.21 pages.

[26] M. Akram and G. Shahzadi, "Operations on single-valued neutrosophic graphs," Journal of Uncertain System, 11, 2017, pp.1-26.

[27] M. Akram," Single-Valued Neutrosophic Planar Graphs," International Journal of Algebra and Statistics Volume 5: 2, pp.157-167, 2016.

[28] M. Akram, and S. Shahzadi,"Neutrosophic soft graphs with application," Journal of Intelligent and Fuzzy Systems, DOI:10.3233/JIFS-16090, 2016,pp.1-18,

[29] M. G. Karunambigai, R. Buvaneswari," Degrees in intuitionistic fuzzy graphs," Annals of Fuzzy Mathematics and Informatics.2016

[30] A. Hassan, M. A. Malik, S. Broumi, A. Bakali, M. Talea, F. Smarandache, "Special Types of Bipolar Single Valued Neutrosophic Graphs, "Annals of Fuzzy Mathematics and Informatics, Vol 14, N1, 2017,pp. in press

[31] M. Mullai, S. Broumi , A. Stephen," Shortest path problem by minimal spanning tree algorithm using bipolar neutrosophic numbers," International Journal of Mathematic Trends and Technology, Vol 46, N2, 2017. pp.80-87

[32] S. Broumi,A. Bakali, M. Talea, F Smarandache and, P.K Kishore Kumar, "Shortest Path Problem on Single Valued Neutrosophic Graphs”, 2017 International Symposium on Networks, Computers and Communications (ISNCC), 2017( in press) 